\title{
Flammability parameters of sprayed and foam aerosols selected for studies
}

\author{
Bozena Kukfisz ${ }^{1, *}$ \\ ${ }^{1}$ The Main School of Fire Service, Faculty of Fire Safety Engineering, 52/54 Slowackiego St., 01-629 \\ Warsaw, Poland
}

\begin{abstract}
The paper presents classification criteria for flammability parameters of sprayed and foamed aerosols [1-3]. Tests were carried out to determine such flammability criteria, as combustion heat of a substance, distance of sprayed aerosol from the ignition source at which ignition takes place, time equivalent necessary for ignition to take place and the density of deflagration for sprayed aerosols. For foamed aerosols the determined parameters comprised combustion heat parameters for a substance, the maximum flame height and the flame retention time. Based on the obtained flammability it may be unequivocally stated that aerosol products pose a serious fire hazard. Aerosols selected for testing pose a serious explosion hazard within a confined space. It seems that from among all the tested aerosols the most hazardous products in this respect comprise solvent and stain remover and DW 40 . Within a space of $200 \mathrm{dm}^{3}$ those products required 3 and 4 seconds of aerosol spraying respectively until the moment of initiating an explosion. Aerosol products in which use was made of propane-butane a carrier gas characterise by very similar flammability and explosivitiy parameters within a closed or confined space.
\end{abstract}

\section{Aerosols - definition of term}

The concept of aerosols had been defined for the first time in 1926 by the Norwegian scientist Eric Rotheim [4]. Thanks to their easy use and productivity aerosols constitute a large group of products available on the market. The first aerosol introduced to mass production was an insecticide, which was meant to protect US troops from mosquitoes. This product was applied in practice for the very first time in $1941[5,6]$.

The hazards of chemicals can be classified using classification criteria that are based on physical, chemical and ecotoxicological endpoints. These criteria may be developed be iteratively, based on scientific or regulatory processes. Recommendation was made at the 1992 Rio Earth summit to develop a globally harmonized chemical hazard classification and compatible labelling system, including material safety data sheets and easily understandable symbols, that could be used for manufacture, transport, use and disposal of chemical substances. This became the globally harmonized system for the Classification and Labelling of Chemicals (GHS). Consistent criteria for categorising chemicals according

\footnotetext{
* Corresponding author: bkukfisz@sgsp.edu.pl
} 
to their toxic, physical, chemical and ecological hazards are now available [1-3]. The European Regulation on classification, labeling, and packaging of substances and mixtures [CLP Regulation (European Commission, EC) No 1272/2008] will align the existing European Union (EU) legislation to the UN-GHS. This CLP Regulation entered into force on January 20, 2009, and will, after a transitional period, replace the current rules on classification, labeling, and packaging for supply and use in Europe. The new hazard classification will introduce new health hazard classes and categories, with associated new hazard pictograms, signal words, Hazard $(\mathrm{H})$-statements, and Precautionary (P)-statements as labeling elements.

Aerosols available on the market for the average consumer have appeared already at the beginning of $1950 \mathrm{~s}$ and have become a major break-through for the cosmetic, pharmaceutical, foodstuff, motorisation, chemical, construction sectors, as well as households. Those products may be contained in diverse type of packaging. This sector is dynamically developing and obtaining new innovative formulas. The concept of aerosol products in accordance with the Regulation of the Minister of the Economy of 5 November 2009 on specific requirements for aerosols [7, 8], defines an aerosol product as a "disposable metal, glass or plastic container comprising compressed air, condensed or dissolved under pressure with liquid, paste, powder, or without them, furnished with a device allowing the release of its contents in the form of solid or liquid particles suspended in gas, such as foam, paste, powder or liquid".

Packaging containing aerosols may consist of metal, glass or plastic containers. Initially the most frequently power gases used in aerosols consisted in freon chlorofluorohydrocarbons $\left(\mathrm{CCl}_{3} \mathrm{~F}, \mathrm{CCl}_{2} \mathrm{~F}_{2}\right)$, which thanks to their durability, nonflammability, inertness and harmlessness to man appeared to be perfect. However, in the 1980s studies on those gases have disclosed their destructive impact on the ozone layer, which protects us from excessive and hazadous UV radiation. This posed a serious problem, and consequently in certain countries the usage of those substances has been prohibited. In Poland the prohibition on the use of those gases has been binding since 1991 . Limiting the use of freon may mean possibilities of improving the state of the environment, albeit not necessarily for the consumer, because the non-toxic and neutral freon has been replaced by such flammable gases as propane or butane. Apart from the above mentioned flammable gases, also carbon dioxide or nitrogen are used as carrier gases.

Flammability of the aerosol, which is based on the chances of the global flame appearance in the aerosol, is mainly controlled by aerosol droplet size and the droplet volume concentration [9]. Hazards of aerosols formed from leaks are classified qualitatively using process pressure and droplet sizes. [10]. Flammable aerosols have created many fire and explosion hazards in the process industry, but the flammability of aerosols has not been fully understood. The minimum ignition energy has been widely used as an indicator for flammability of combustible mixtures, but the amount of experimental data on the minimum ignition energy of aerosols is very limited [11]. For example, the method used in research work has the potential to prediction of the minimum ignition energy of aerosol [12]. Aerosol combustion, especially for high-flash point materials, is a very complicated phenomenon inclusive of droplet evaporation, temperature increase, flame formation, flame propagation, and flame quench. Ignition delay will be beneficial to the mitigation timing and detector sensor setting of facilities to prevent aerosol cloud fires [13].

According to the CLP regulations [15], products meeting the following criteria may be categorised to the category of aerosol products: liquid substances with ignition temperature of $\leq 93^{\circ} \mathrm{C}$, flammable gases (within flammability range in the air at a temperature of $20^{\circ} \mathrm{C}$ and at normal pressure of $101.3 \mathrm{kPa}$ ), flammable solid substances (which easily become ignited or may cause ignition or as a result of friction may cause ignition or contribute to 
combustion. Flammable solid substances include also powdered, granulated or paste-like substances or mixtures, which are hazardous, if they may easily become ignited as a consequence of short-ter, contact with the ignition source, such as a burning match, and if the flame spreads quickly) [14]. If an aerosol comprises an ingredient that may be considered as easily flammable, the entire mixture shall be considered as flammable. Flammable ingredients do not include pyrophoric self-heating substances or reacting with water. Those substances do not occur in mixtures for the production of aerosols. Diagrams shown on figures 1, 2 and 3 illustrate the classification criteria for aerosols, spray aerosols and foam aerosols.

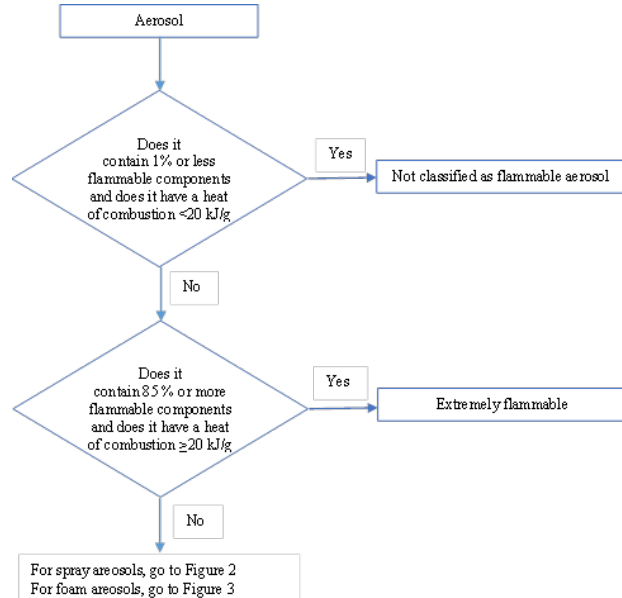

Fig. 1. Diagram showing the procedure for classification of flammable aerosols [14].

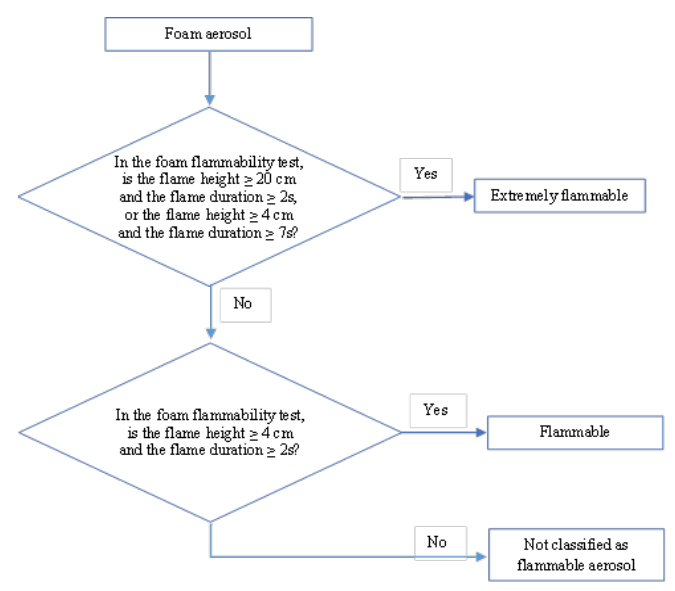

Fig. 3. Diagram showing the procedure for classification of foam aerosols [14].

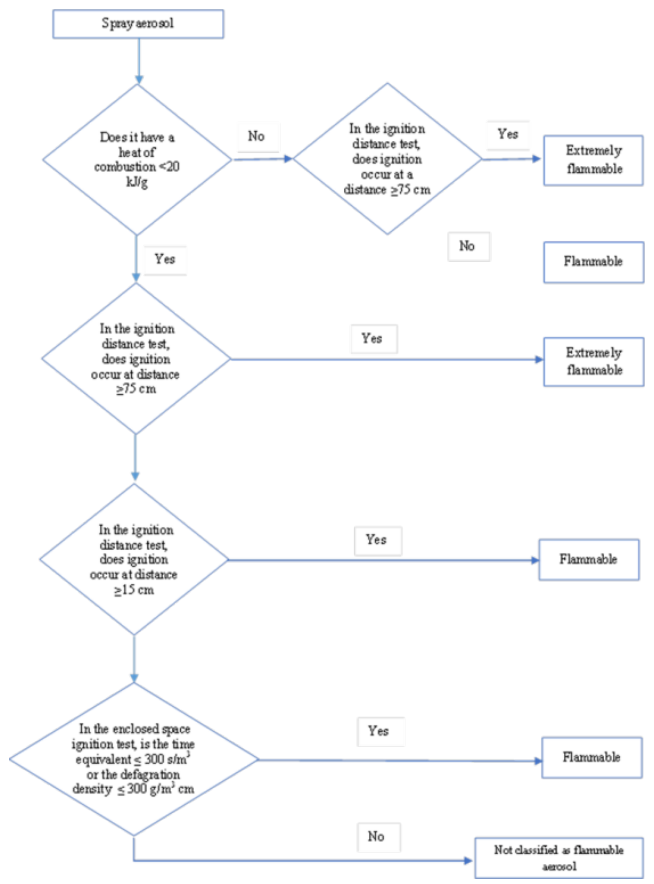

Fig. 2. Diagram showing the procedure for classification of spray aerosols [14]. 


\subsection{Properties of tested aerosol products}

\subsubsection{Determination of combustion heat}

The types of aerosols used in testing have been selected from the cosmetic, pharmaceutical, construction, automotive sectors, and are used in households; moreover they are generally accessible for the average consumer. Testing of combustion heat according to standard PNEN ISO 1716:2018 has been carried out for the following aerosols: Bros (insecticide), repair zinc, DW 40, Pepper Spray, Lack Kiler (formulation for removal of paints and varnishes), Nivea anti-perspirant, Plak, Panthenol 10\%, Nivea (shaving foam) solvent and stray remover and Taft (hair spray). Result of the performed tests allowed the presumption that the method consistent with standard [15] does not allow the determination of combustion heat of Nivea shaving foam. Following completion of testing no traces of sample combustion have been observed. This could be caused by the contents of only $4 \%$ by weight of easily flammable ingredients and high water contents inside, which rendered impossible initiating of combustion by the electric spark. The remaining aerosols have undergone complete combustion. As a result of testing, data were obtained that allow calculating combustion heat of the given sample, which have been presented in table 1 .

Table 1. Results of testing of combustion heat of selected aerosols.

\begin{tabular}{|c|c|}
\hline Tested aerosol product & Average combustion heat [MJ/kg] \\
\hline Bros & 37.51 \\
\hline Repair zinc & 28.03 \\
\hline DW 40 & 42.81 \\
\hline Pepper spray & 22.70 \\
\hline Lack Kiler & 31.74 \\
\hline Nivea anti-perspirant & 40.15 \\
\hline Plak & 39.36 \\
\hline Solvent and stain remover & 32.84 \\
\hline Taft hair spray & 28.32 \\
\hline Assembly foam & 27.88 \\
\hline Panthenol 10\% & 3.61 \\
\hline Taft hair foam & 3.43 \\
\hline
\end{tabular}

On the basis of obtained test results it was ascertained that sprayed aerosols selected for needs of testing are characterised by high values of combustion heat. The highest test obtained values have been recorded for aerosol DW 40 and Nivea anti-perspirant. DW 40 has obtained the value of combustion heat equalling to $42.81 \mathrm{MJ} / \mathrm{kg}$. Anti-perspirant Nivea has obtained the value of $40.14 \mathrm{MJ} / \mathrm{kg}$. On the other hand, the lowest value of combustion heat of sprayed aerosols equalling to $22.7 \mathrm{MJ} / \mathrm{kg}$ was recorded for pepper spray. As regards foamed aerosols the highest combustion heat was recorded for assembly foam, the value of which equals to $27.88 \mathrm{MJ} / \mathrm{kg}$. The two remaining foams: Panthenol $10 \%$ and the Taft Hair Foam, for which obtained were results have similar values of combustion heat equalling to $3.61 \mathrm{MJ} / \mathrm{kg}$ and $3.43 \mathrm{MJ} / \mathrm{kg}$ respectively.

\subsubsection{Testing ignition at a distance}

Testing ignition from a distance had been performed for the following aerosol products: Bros (insecticide), repair zinc, DW 40, Pepper Spray, Lack Kiler (formulation for removal of paints and varnishes), Nivea anti-perspirant, Plak, solvent and stray remover and Taft (hair spray). Results of tests were presented in table 2. 
Table 2. Results of tests of ignition from a distance of selected aerosols.

\begin{tabular}{|c|c|c|}
\hline Tested aerosol & $\begin{array}{c}\text { Distance at which ignition } \\
\text { of sprayed aerosol took } \\
\text { place from a full container } \\
\text { [cm] }\end{array}$ & $\begin{array}{c}\text { Distance at which ignition of sprayed } \\
\text { aerosol took place from a container } \\
\text { filled up to 10- } \mathbf{1 2 \%} \text { by weight of } \\
\text { nominal filling [cm] }\end{array}$ \\
\hline Bros & 45 & 60 \\
\hline Zinc & 30 & 30 \\
\hline DW 40 & 90 & 90 \\
\hline Pepper spray & 60 & 45 \\
\hline Lack Kiler & 90 & 90 \\
\hline Nivea anti-perspirant & 45 & 30 \\
\hline Plak & 90 & 90 \\
\hline Solvent and stain remover & 90 & 90 \\
\hline Taft hair spray & 90 & 75 \\
\hline
\end{tabular}

Based on the obtained results it has been ascertained that al the selected aerosol products pose a significant fire hazard. In addition it should be borne in mind that the obtained flammability results at a distance for aerosols: DW 40, Lack Kiler, Solvent and stain remover, Plak and Taft (hair spray) allow their classification to the first category of fire hazard described as "Hazard". At a maximum tested distance of sprayed aerosol from the burner, which amounts to $90 \mathrm{~cm}$, those products would become ignited, It should be borne in mind that those products, emptied to $10-12 \%$ of volume of nominal filling level still became ignited at a distance that qualified them to the first category of fire hazard. Among those five aerosols posing the most severe hazard the aerosol used as solvent and stain remover stands out most. This product is characterised by such a high combustion intensity that during 5 second duration of a single attempt at testing the flame almost reached the dispenser spraying the agent, which has several times imposed premature completion of the testing.

The remaining sprayed aerosols: Bros (insecticide), repair zinc, pepper spray and Nivea anti-perspirant are classifiable to the second category with view to the fire hazard denoted as "Caution". As compared to aerosols qualified to the second category, Bros insecticide stands out most. This product, when emptied to $10-12 \%$ of the nominal filling level, is characterised by the bigger distance, at which ignition took place than as for a full container. This fact may caused by the carrier gas used in this aerosol consisting of condensed propane-butane-isobutene. During spraying of a full container a bigger amount is released of liquid contents used for disinfection of insects which is clearly less flammable than the carrier gas used in this product.

\subsubsection{Testing ignition in closed space}

Testing ignition within a closed space was carried out for the following sprayed aerosols: Bros (insecticide), repair zinc, DW 40, Pepper Spray, Lack Kiler (formulation for removal of paints and varnishes), Nivea anti-perspirant, Plak, solvent and stray remover and Taft (hair spray). Results of tests were presented in table 3. 
Table 3. Results of tests of ignition in closed space of selected aerosols.

\begin{tabular}{|l|c|c|c|c|}
\hline Tested aerosol product & $\begin{array}{l}\text { Time needed for } \\
\text { ignition to take } \\
\text { place [s] }\end{array}$ & $\begin{array}{l}\text { Mass } \\
\text { loss [g] }\end{array}$ & $\begin{array}{l}\text { Time } \\
\text { equivalent } \\
{\left[\mathbf{s} / \mathbf{d m}^{\mathbf{3}}\right]}\end{array}$ & $\begin{array}{l}\text { Deflagration } \\
\text { density }\left[\mathbf{g} / \mathbf{d m}^{\mathbf{3}}\right]\end{array}$ \\
\hline Bros & 9 & 8.7 & 43.7 & 42.3 \\
\hline Repair zinc & 18 & 11.1 & 87.4 & 53.9 \\
\hline DW 40 & 4 & 4.0 & 19.4 & 19.3 \\
\hline Pepper spray & 61 & 47.7 & 296.1 & 231.6 \\
\hline Lack Kiler & 13 & 10.6 & 63.1 & 51.4 \\
\hline Nivea anti-perspirant & 14 & 8.5 & 68.0 & 41.3 \\
\hline Plak & 12 & 7.5 & 58.3 & 36.6 \\
\hline Solvent and stain remover & 3 & 3.2 & 14.6 & 15.5 \\
\hline Taft hair spray & 16 & 12.2 & 77.7 & 59.1 \\
\hline
\end{tabular}

On the basis of obtained results in the process of flammability testing performed within a closed space it was found that all the selected aerosols pose a fire hazard and may be categorised to at least the second fire hazard category. From among the selected aerosols, the biggest hazard within a closed or confined space is posed by solvent and stain remover. This product already after 3 seconds caused explosion within a space of $200 \mathrm{dm}^{3}$ and released only 3.187 grams of the product, reaching the time equivalent equalling to 14.563 $\mathrm{s} / \mathrm{dm}^{3}$, and deflagration density of $15.47 \mathrm{~g} / \mathrm{dm}^{3}$. It should be emphasised that in order for an aerosol to be classified to the third flammability category it must have a higher time equivalent to $300 \mathrm{~s} / \mathrm{dm}^{3}$ and a higher deflagration density than $300 \mathrm{~g} / \mathrm{dm}^{3}$. It has been ascertained that pepper spray was the closest to that limit from among all the tested aerosols, and consequently has proven to be the least flammable. The time required for ignition to take place in a closed space or a confined space equalled to 61 seconds and required spraying as much as 47.7 grams of the product. The time equivalent for this product was close to the limit of the third flammability category and amounted to 296.1 $\mathrm{s} / \mathrm{dm}^{3}$. The deflagration density equalled to $231.6 \mathrm{~g} / \mathrm{dm}^{3}$.

\subsubsection{Analysis of results of flammability tests of selected foam types}

Testing the flammability of foal was performed for the follow foamed aerosols: Assembly foam, Nivea shaving foam, Taft (hair foam) and Panthenol 10\%. As regards the Nivea shaving foam, no ignition had been achieved during the testing. Despite preparation of new samples and leaving the released product for 30,60,120, 240 seconds respectively bfore applicator of the source of ignition to the foam edge, no foam ignition has been achieved.

Table 4. Results of tests of types of foam of selected foamed aerosols.

\begin{tabular}{|c|c|c|c|c|c|}
\hline Tested foam type & $\begin{array}{l}\text { Sample } \\
\text { No. }\end{array}$ & $\begin{array}{l}\text { Time of } \\
\text { flame } \\
\text { retention [s] }\end{array}$ & $\begin{array}{l}\text { Maximum } \\
\text { flame height } \\
{[\mathrm{cm}]}\end{array}$ & $\begin{array}{l}\text { Average time } \\
\text { of flame } \\
\text { retention [s] }\end{array}$ & $\begin{array}{l}\text { Average } \\
\text { flame height } \\
\text { [cm] }\end{array}$ \\
\hline \multirow{3}{*}{ Assembly foam } & 1 & 48 & 18 & \multirow{3}{*}{ 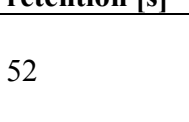 } & \multirow{3}{*}{16,3} \\
\hline & 2 & 57 & 15 & & \\
\hline & 3 & 51 & 16 & & \\
\hline \multirow{3}{*}{ Panthenol 10\% } & 1 & 2 & 31 & \multirow{3}{*}{2} & \multirow{3}{*}{31,3} \\
\hline & 2 & 2 & 30 & & \\
\hline & 3 & 2 & 33 & & \\
\hline \multirow{3}{*}{ Taft foam } & $\frac{3}{1}$ & 25 & 20 & \multirow{3}{*}{26,7} & \multirow{3}{*}{18,3} \\
\hline & 2 & 28 & 16 & & \\
\hline & 3 & 27 & 19 & & \\
\hline
\end{tabular}


Based on the obtained test results of the flammability of foam of selected aerosols a presumption may be made that the biggest fire hazard with view to flammability is posed by assembly foam. This particular product is characterised by the longest time of flame retention equalling on average to 52 seconds. It should be additionally emphasised that smoke generated as a result of combustion of this foam is dense and black. It was found that the Panthenol 10\% foam has the highest flame height which equalled on average to $31.3 \mathrm{~cm}$. This product has achieved the shortest time of flame retention of 2 seconds, which is the minimum limit that qualifies foamed aerosols to the second category of fire hazard. The Taft hair foam has achieved the maximum flame height in 20 seconds and the flames have been retained on average for 20 seconds and flames were retained o average for 26.7 seconds for a 5-gram sample.

\subsection{Summary of tests of aerosol products}

The article presents criteria for classification of flammability parameters of sprayed and foamed aerosol products, and a presentation was made of results of testing that determined such flammability parameters as: combustion heat of a substance, distance of a sprayed aerosol from ignition source at which ignition takes place, time equivalent needed for ignition to take place, and density of deflagration for sprayed aerosols. As regards foamed aerosols, determination was made of the combustion heat of a substance, maximum flame height and time of flame retention. On the basis of the obtained flammability parameters a presumption may be clearly made that aerosols pose a serious fire hazard. From among twelve selected aerosols available in each household, only the Nivea shaving foam did not manifest flammable properties and had been classified to the third category with view to fire hazard. It should be emphasised, however, that the non-flammable shaving foam, similarly as all products subjected to high pressure may burst under the impact of thermal action. Following an analysis of the obtained results of combustion heat and allowing for results of ignition at a distance, the following sprayed aerosols have been classified to the first category that poses the biggest fire hazard: DW 40, Lack Kiler (formulation for removal of paints and varnishes), Plak, Taft (hair spray) and Solvent and Stain Remover. Foamed aerosols classified to the first category based on results of flammability testing of foam included assembly foam, Panthenol $10 \%$ and Taft hair foam. Based on the obtained results the following have been classified to the second category of fire hazard: Bros (insecticide), repair zinc, pepper spray and Nivea anti-perspirant.

Aerosols selected for needs of studies posed a significant explosion hazard in a closed space. From among the tested aerosols the most hazardous in this respect are solvent and stain remover and DW 40. Within a space of $200 \mathrm{dm}^{3}$ those products needed 3 and 4 seconds respectively of aerosol spraying until initiation of an explosion.

Such results prove the existence of considerable issues connected with storage and transport of a larger amount of those products. Certain aerosols contain hazardous substances that pose additionally a hazard connected with their toxicity. Substances toxic for people have been classified, according to the ADR agreement, to class 6.1 based on toxic properties. This classification has been based on results of tests of values of $\mathrm{LC}_{50}$ and $\mathrm{LD}_{50}$ carried out on animals.

Post-consumer aerosol cans are being recovered for recycling through material reclamation facilities (MRFs). The general conclusion of the risk assessments reviewed is that although potential hazards arise from flammable or harmful residual contents, empty aerosol containers may be included in the domestic post-consumer waste recycling stream provided a number of basic precautions are taken to control risks to an acceptable level. Principle amongst these precautions is that only empty aerosols derived from the domestic 
waste stream should be handled by a MRF and these should not be segregated from the steel and aluminium streams [16].

\section{References}

1. R. De Groot, P. Brekelmans, J. Herremans, J. Meulenbelt, Clinical Tox. 48, (2010)

2. U. Klaschka, Internat. J. Hygiene Environ. Health 213, 4, (2010)

3. U. Klaschka, Dangerous cosmetics - criteria for classification, labelling and packaging (EC 1272/2008) applied to personal care products, Environmental Sciences Europe, Bridging Science and Regulation at the Regional and European Level, 24, (2012)

4. A. Williams, Combustion of liquid fuel sprays (MA: Butterworths, Boston, 1990)

5. Y. Ko, R.W. Anderson, V.S. Comb. Flame 83, (1991)

6. A. Maragkos, P.J. Bowen, Combustion hazards due to impingement of pressurized releases of high-flashpoint liquid fuels, Proceedings of the Combustion Institute, 29, (2002)

7. Regulation of the Minister of Economy of 5 November 2009 on specific requirements for aerosols (Polish Journal of Laws/Dz. U. No. 188, item 1460)

8. Notice of the Minister of Economy of 26 May 2015 on announcement of a harmonised text of the Minister of Economy on specific requirements for aerosols

9. P. Lian, A. F. Mejia, Z. Cheng, M. Ssm Mannan, J. Loss Prevention in the Poroc. Ind. 23, 2, (2010)

10. K. Krishna, T.K. Kim, K.D. Kihm, W.J. Rogers, M. Sam Mannan, J. Loss Prevention in the Poroc. Ind. 16, 1, (2003)

11. K. Krishna, W. J. Rogers, M. Sam Mannan, J. Hazardous Materials, 104, 1, (2003)

12. P. Lian, X. Gao, M. Sam Mannan J. Loss Prevention in the Poroc. Ind. 25, 1, (2012)

13. S. Huang, X. Li, M. Sam Mannan, J. Loss Prevention in the Poroc. Ind. 26, 6, (2013)

14. Regulation (EC) No. 1272/2008 of the European Parliament and the Council of 16 December 2008 on the classification, labelling and packaging of substances and mixtures, amending and revoking Directive 67/548/EEC and 1999/45/EC and amending regulation (EC) No. 1907/2006 (Official Journal L 353 of 31 December 2008 , p. 1 , as amended)

15. PN-EN ISO 1716:2018

16. D. N. Smith, D. Linton, Conser. Recyc. 31, 3, (2001) 